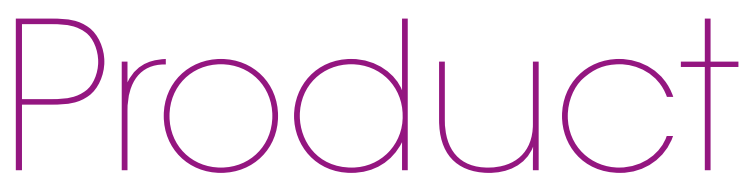

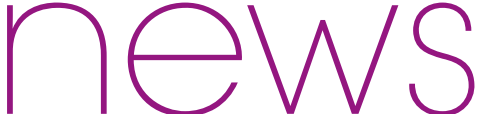

Product news is provided as a service to readers using text and images from the manufacturer, supplier or distributor and does not imply endorsement by BDJ Team. Normal and prudent research should be exercised before purchase or use of any product mentioned.

\section{GOOD FOR YOU AND KIND TO THE PLANET}

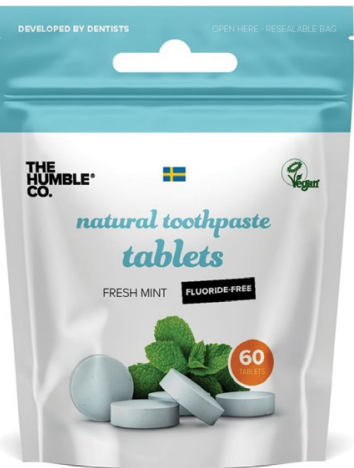

Humble is a

health and

wellness company offering reliable and innovative products that are good for you and kind to the planet. The Humble Brush (the world's most sold bamboo toothbrush) has a handle made from $100 \%$ biodegradable, sustainably grown bamboo. The bristles are made of nylon- 6 bristles from Dupont. The packaging is eco-friendly, the box and inside wrapper are made from recycled materials and can be thrown out with organic waste. This toothbrush is vegan, cruelty-free and verified BPA free.

Humble's fluoride free Toothpaste Tablets are basically regular toothpaste, minus the water. This means that the brand can save on water - there's now no need to ship regular tap water around the globe because there's plenty of water in your tap already to make this tablet to toothpaste. To use, just bite the tablet and brush as usual.

Humble's Mint Dental Floss (50M) is a dentist-approved roll of dental floss in a cardboard pack; made from nylon it slides easily between your teeth without shredding or breaking. The floss is coated with a mint flavouring as well as xylitol, to ensure that your flossing experience is as efficient, pleasant and effective as possible.

Bamboo Toothpicks are made from $100 \%$ biodegradable, sustainably-grown bamboo. The packaging is eco-friendly and the box and inside wrapper are made from recycled materials.

Finally, Humble's stylish Interdental Brush, with a handle from $100 \%$ sustainably grown bamboo and with quality nylon bristles from DuPont, provides an easy and practical alternative to flossing.

\title{
BUILDING STRONG DEFENCES
}

Arm \& Hammer Enamel Repair baking soda toothpaste provides the perfect formula to help patients combat acid erosion, and maintain strong and healthy teeth.

We know that acid attack and erosion can be a losing battle for some patients. The clinically proven baking soda and Liquid Calcium formula of Enamel Repair Toothpaste sets up the perfect defence by filling in tooth crevices and restoring enamel surfaces in five days, offering unrivalled protection.

To give your patients a helping hand in tackling acid erosion and building a strong and healthy mouth, look no further than Arm \& Hammer Enamel Repair baking soda toothpaste.

For more information about the carefully formulated Arm \& Hammer toothpaste range, visit https://www.armandhammer. co.uk/ or email: ukenquiries@ churchdwight.com.

Arm \& Hammer oral healthcare products are available at Boots, Superdrug, Sainsbury's, Tesco, Asda and Morrisons throughout the UK.

\section{British Dental Conference \& \\ Dentistry Show \\ Birminghan \\ 13-14 May 2022 I NEC I Hall 5}

May 222

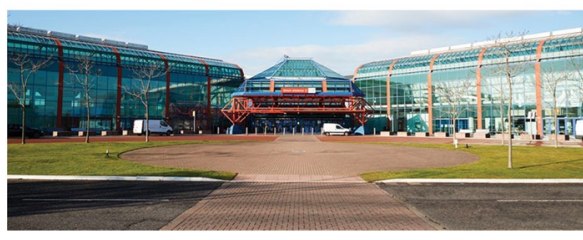

\section{THE PLACE TO BE THIS MAY}

This May, the British Dental Conference and Dentistry Show Birmingham is hosting the most essential UK event for dentistry once more!

This event's breadth of exhibitors, speakers and content hours covers all bases within dentistry, so there's a little something for everyone.

Tackling the challenges thrown at you is made easier when you have the insight and expertise to lead the way - delegates have 100 hours of free enhanced CPD to choose from, and the chance to network with fellow professionals. Sharing ideas, questions and experiences has never been easier!

So, save the date and attend this May 2022 !

The next British Dental Conference and Dentistry Show Birmingham will be held on Friday 13 and Saturday 14 May 2022, Birmingham NEC, co-located with DTS.

For more information, visit https:// birmingham.dentistryshow.co.uk/or email dentistry@closerstillmedia.com.

If you would like to promote your products or services direct to the dental industry in BDJ Team, call Andy May on 02078434785 or emaila.may@nature.com. 